\title{
The Components of Sideward Movement in the Verb Copying Construction in Mandarin Chinese
}

Pei-Jung Kuo

Department of Foreign Languages, National Chiayi University

\begin{abstract}
In this paper, I explore the components of the sideward movement involved in the verb copying construction proposed by Cheng (2007). I first present some facts of the resultative $d e$-clause of the verb copying construction which seems to be puzzling under Cheng's analysis. An extended analysis is then proposed. Under the extended analysis, I propose that the sideward movement mechanism involved in the resultative $d e$-clause can be further analyzed as internal topicalization plus differential object marking. This analysis of sideward movement is also attested in the manner $d e$-clause of the verb copying construction. The proposed components relate the sideward movement in the verb copying construction to the syntactic mechanisms which are also observed widely in Mandarin Chinese and other languages.
\end{abstract}

\section{Keywords}

verb copying, standard movement, sideward movement, internal topicalization, differential object marking, BA construction

Studies in Chinese Linguistics, Volume 36, Number 1, 2015, 35-58 DOI: 10.1515/scl-2015-0003 (C) 2015 by T.T. Ng Chinese Language Research Centre, Institute of Chinese Studies, The Chinese University of Hong Kong 


\section{Introduction}

The verb copying construction in Mandarin Chinese is quite intriguing and received a lot of attention in the literature (see Li and Thompson 1981, Huang 1982, 1984, Gouguet 2006, Fang and Sells 2007, Cheng 2007, Hsu 2008, Tieu 2009 and others). The following resultative $d e$-clause in (1) is one subtype of the verb copying construction. Two main characteristics of the resultative de-clause can be found in this example. First, the main verb in example (1) is repeated as shown in bold. In addition, example (1) is noted to be ambiguous:

(1) Zhangsan qi nei-pi ma qi de hen lei.
Zhangsan ride that-Cl horse ride DE very tired
'Zhangsan rode that horse and the horse got very tired.' or
'Zhangsan rode that horse and became tired as a result.'

The two different interpretations mainly lie in the question of whether the man or the horse is tired. The first reading is the "object-result" reading since it is the horse (the object) that got tired. The other one is the "subject-result" reading. That is, the subject Zhangsan got tired because of the horse-riding event. Adopting the framework of movement and realization of multiple copies in Nunes (2004), Cheng (2007) argues that these two readings should involve two different derivations. The "object-result" reading is the result of NP movement plus verb movement (standard movement under Cheng's term), while the "subject-result" reading is a case of sideward movement (see Nunes 2001, 2004).

The derivation for the "object-result" reading proposed by Cheng (2007) is shown in (2) and (3):
a. $[\mathrm{vP}$
b. $[\mathrm{VP}$

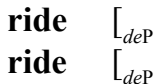
DE that horse very
tired ]]
DE $t_{i} \quad$ very tired ]]

In (2a), the $d e \mathrm{P}$ heads a clause where the NP horse is the subject. The NP horse undergoes movement to Spec, VP as in (2b). At this point, Cheng argues that one can insert $b a$ at the $v$ head position to form a BA construction as in (3a) (see also Huang 1997 and Lin 2001). If there is no BA insertion, the verb can undergo movement (Copy + Merge) instead as in (3b) (see Chomsky 1995 and Huang, Li and Li 2009). Note that in (3b), both copies of the verb are pronounced. The original copy merges with $d e$ in the $d e \mathrm{P}$ and therefore becomes distinct from the second copy and can by linearized under L(inear) C(orrespondence) A(xiom) (see Kayne 1994). According to LCA, the partial sequence $\sigma=<$ ride, that horse, ride $>$ in (3b) cannot be linearized if the lower copy is not fused with $d e$. Without the fusion, that horse is predicted to precede and be preceded by the same element ride. Lacking of 
asymmetry, $\sigma$ cannot be linearized. ${ }^{1}$ Since the two copies in (3b) are not identical and distinct from each other because of the fusion morphologically, both of them can be pronounced. This structure in $(3 b)$ then forms the verb copying pattern. ${ }^{2}$

(3) a. $\left[_{v \mathrm{P}} \mathrm{Z}\right.$. ba $\left[_{\mathrm{VP}}\right.$ that horse ${ }_{\mathrm{i}}$ ride $\left[{ }_{d e \mathrm{P}}\right.$ de $\mathrm{t}_{\mathrm{i}}$ very tired $\left.\left.]\right]\right]$

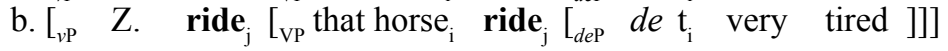

As for the "subject-result" reading, the initial merged structure is shown in (5a). The subject originates from the resultative $d e$-clause and raises to the Spec, TP position as in the ergative cases. Note that there is no $v \mathrm{P}$ or Spec VP to host the object because Cheng suggests that resultatives can optionally trigger an ergative shift in the structure of the VP (see Hoekstra and Mulder 1990). Hence, Cheng proposes that sideward movement is involved for the "subject-result" reading. The idea of sideward movement is based on decomposing Move as Copy and Merge. As illustrated in (4a), a copy of $\alpha^{i}$ is made and merges with another syntactic object $\left[{ }_{L} \ldots\right]$ being built. A constituent $\left[{ }_{M} \alpha^{i}\left[{ }_{L} \ldots\right]\right]$ in (4b) is formed and will enter the structure later. Hence for the "subject-result" reading, the verb in (5a) is copied, and merges with the object NP in (5b) separately and forms a VP as in (6b). This VP then merges with the original VP by adjoining to it, and the final structure is shown in (7).
a. $\left[{ }_{K} \ldots \alpha^{\mathrm{i}} \ldots\right]$

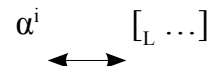
Copy
b. $\left[{ }_{\mathrm{K}} \ldots \alpha^{\mathrm{i}} \ldots\right]$

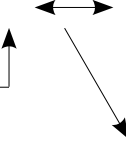

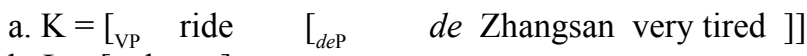
b. $\mathrm{L}=\left[_{\mathrm{NP}}\right.$ horse $]$

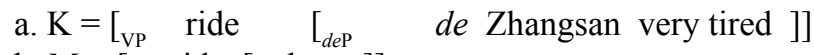

b. $\mathrm{M}=\left[_{\mathrm{VP}}\right.$ ride $\left[_{\mathrm{NP}}\right.$ horse $\left.]\right]$

$\left[_{\mathrm{TP}} \mathrm{Z}_{{ }_{\mathrm{i}}}\left[_{\mathrm{VP}}\right.\right.$ ride that horse $]\left[_{\mathrm{VP}}\right.$ ride $\quad\left[_{d e \mathrm{P}}\right.$ de $\mathrm{t}_{\mathrm{i}}$ very tired $\left.\left.]\right]\right]$

In the following discussion, I will argue that structure (7) needs further elaboration to accommodate some interesting facts regarding the resultative declause of the verb copying construction. Therefore, in Section 2, I first present some facts/puzzles that cannot be explained by Cheng's (2007) analysis for the

\footnotetext{
Note that for Cheng (2007), the term "fusion" is defined under the framework of Distributed Morphology (Halle and Marantz 1993, Halle and Marantz 1994 and Halle 1997) as a post-syntactic operation. The higher copy of the verb is copied and merged via syntactic operations happens before the fusion of the lower copy of the verb and the $d e$-clause.

2 According to Cheng (2007), the lower copy of the verb is fused with de morphologically. Therefore, LCA cannot see the inner elements of the fused unit and, thus, treats V and $\left[_{v} \mathrm{~V}-d e\right]$ as distinct.
} 
resultative de-clause of the verb copying construction. In Section 3, I propose an extended analysis and explore the nature of the object NP and the copied verb involved in the derivation. I propose that the object NP in (7) is a case of internal topicalization, and the copied verb is a case of differential object marking. In Section 4, I show that the derivation proposed for the manner de-clause in the verb copying construction also involves internal topicalization and differential object marking. I conclude the paper in the last section.

\section{Some facts and puzzles}

In this section, I present some facts/puzzles regarding the "subject-result" reading of the resultative $d e$-clause. These facts/puzzles then urge us to rethink the proposed analysis for the resultative de-clause of the verb copying construction by Cheng (2007).

First of all, the structure in (7) implies that the copied verb and the definite object NP (the V-O combination henceforth) are within the VP domain since the $\mathrm{V}-\mathrm{O}$ combination containing both of them adjoins to VP in (7). ${ }^{3}$ However, there are cases indicating that their syntactic position can be higher than the VP-adjoined position. For instance, Hsu (2008) proposes that the V-O combination should be higher than the VP domain. She points out that the V-O combination can be higher than epistemic and deontic modals as in (8) and is never lower than the BA NP in a BA construction as in (9). ${ }^{4}$ For Hsu (2008), the $\mathrm{V}-\mathrm{O}$ combination is proposed to be an internal topic and is located in a Topic Projection between TP and $v$ P.

(8)
Zhangsan qi
na-pi ma
yinggai/hui qi de hen lei.
Zhangsan ride
that- $\mathrm{Cl}$ horse should/can ride $\mathrm{DE}$ very tired
'Zhangsan should/would become very tired after riding that horse.'

(9) Zhangsan [xuanlian ma] ba ma [*xuanlian ma] xuanlian de hen lei. Zhangsan train horse BA horse train ma train DE very tired 'Zhangsan trained horses and the horses became very tired.'

In the literature, Tsai $(2009,2010)$ proposes that epistemic and deontic modals are in the TP domain and therefore mark the $v \mathrm{P}$ periphery. In example (8), the copied verb and the object NP cannot be lower than the $v \mathrm{P}$ domain since they are higher the

3 In Cheng (2007), the copied verb and the object NP forms a VP via sideward movement. However, based on the analysis that I am going to discuss below, I will use the term "V-O combination" to refer to the "VP" containing the copied verb and the object NP throughout the paper. The reason behind this choice will be clear after my analysis is presented.

4 A similar test from the lian...dou construction also indicates that the copied verb and the object NP can be located in the TP domain, where dou ('all') marks the $v$ P periphery (Shyu 1995).

(i) Zhangsan lian qi na-pi ma dou qi de hen lei

Zhangsan even ride that- $\mathrm{Cl}$ horse all ride $\mathrm{DE}$ very tired

'Zhangsan even became very tired when riding that horse.' 
modals. Moreover, Hsu (2008) adopts Li's (2006) analysis for the BA construction. $\mathrm{Li}$ (2006) argues for an independent BA projection right above $v$ P. Hence example (9) indicates that the $\mathrm{V}-\mathrm{O}$ combination should be higher than $v \mathrm{P}$. Hsu's proposal, therefore, explains these two pieces of fact easily since for her, the V-O combination is located in a TopicP in the TP domain. On the other hand, she claims that it is not clear how Cheng's analysis can accommodate these two pieces of fact. ${ }^{5}$

Second, Cheng (2007) also discusses the following kind of sentences of the resultative $d e$-clause. As noted by Cheng, only a "subject-result" reading is available in example (10) and the V-O combination has a non-specific indefinite reading.

$\begin{array}{llllll}\text { Zhangsan qi ma qi de } & \text { hen } & \text { lei. } \\ \text { Zhangsan ride horse ride } & \text { DE } & \text { very } & \text { tired } \\ \text { 'Zhangsan rode and became very tired.' } & & \end{array}$

However, it is not the case that all indefinites are acceptable in the resultative declause. Note that the indefinite object in example (10) is a bare noun. If the indefinite NP is like one in (11) with a numeral and a classifier (NPs with bare numeral determiners as termed in Liu 1997), the sentence becomes ungrammatical. ${ }^{6}$
*Zhangsan
yi-pi ma
qi
de hen
lei.
'Zhangsan rode a horse and became very tired.'

Under Cheng's (2007) analysis, example (11) should be able to be derived via sideward movement since nothing bans the merge between a copied verb and an object NP with a numeral determiner. However, the ungrammaticality of (11) is unexpected and cannot be excluded via sideward movement.

The last fact regarding the resultative de-clause of the verb copying construction is also worth considering. Huang, $\mathrm{Li}$ and $\mathrm{Li}$ (2009) note that the copied verb can be omitted as in (12). With or without the copied verb, the meaning of the sentence remains almost the same.

\footnotetext{
5 Hsu (2008) has other arguments against the VP-adjunction proposal by Cheng (2007). I only present the first two arguments here because of their relevance to the current proposal.

6 The same phenomenon can also be observed in the BA construction ( $\mathrm{Li}$ and Thompson 1981). The explanation for this particular restriction is due to a shared property between the verb copying construction and the BA construction, which I will propose later in the discussion. Also note that this indefinite NP with a numeral determiner in (11) and the ones shown in the following repeated/ relevant examples throughout the paper are indefinite "non-specific" NPs. As pointed out by one of the reviewers, if a specific reading is involved, the sentences can become acceptable even if the NPs are indefinite ones with numeral determiners.
} 


$\begin{array}{lllll}\text { Zhangsan (da) na-pi ma da de } & \text { hen lei. } \\ \text { Zhangsan hit that-Cl horse hit } & \text { DE } & \text { very tired } \\ \text { 'Zhangsan hit that horse and became very tired.' } & \end{array}$

However, the omission of the copied verb is not totally free. For example, the copied verb cannot be omitted in the following example (13) if the original meaning of the sentence needs to be maintained (see also Lu 1994).?

$\begin{array}{lllllll}\text { Zhangsan } & *(\mathbf{d a}) & \text { Lisi } & \text { da } & \text { de } & \text { hen } & \text { lei. } \\ \text { Zhangsan beat } & \text { Lisi } & \text { beat } & \text { DE } & \text { very } & \text { tired } \\ \text { 'Zhangsan hit Lisi and became very tired.' } & & \end{array}$

Although the original meaning cannot be maintained while the copied verb is omitted, the example in (13), in fact, can be grammatical with a totally different meaning. That is, the NP Lisi has to be interpreted as the subject, while the NP Zhangsan becomes the object as in (14).

Zhangsan Lisi da de hen lei.
Zhangsan Lisi beat DE very tired
'Zhangsan, Lisi beat him and became very tired.'

Importantly, it would be hard for Cheng (2007) to explain this contrast between (12) and (13). The only difference between these two sentences lies in the objects following the copied verb: a [ \pm human] distinction.

To summarize, in this section, I have discussed three related phenomena about the "subject-result" reading of the resultative de-clause of the verb copying construction. The copied verb and the object NP can be higher than the $\nu \mathrm{P}$ domain according to Hsu (2008). Moreover, the sideward movement analysis for the indefinite bare noun cannot explain the impossibility of indefinite NPs with bare numeral determiners. There is also no explanation for the optional copied verb and its correlation with the $[ \pm$ human] object NP. It then would be interesting to see how these three puzzles/facts can be accounted by any analysis of the verb copying construction.

\footnotetext{
As one of the reviewers points out, if an emphatic stress is placed on "Lisi", "Lisi" can still function as the object no matter the copied verb is omitted or not. However, this possibility is due to the emphatic stress on "Lisi" which turns "Lisi" into a contrastive focus. This intervening factor of emphatic stress has to be put aside for the current discussion. Under the neutral intonation, "Lisi" in example (13) is interpreted as the subject as noted.
} 


\section{The proposal}

\subsection{The position of the $\mathrm{V}-\mathrm{O}$ combination}

In this section, based on Cheng's analysis, I will make an extended proposal to explain the three observed facts/puzzles discussed in Section 2. Following Cheng (2007), I believe that sideward movement is needed for the "subject-result" reading of the resultative $d e$-clause of the verb copying construction. However, I propose that the landing site of the V-O combination is not restricted within the VP domain, but could range from the VP periphery to the TP domain (i.e. an extension of Cheng's original VP-adjunction proposal within the TP domain). ${ }^{8}$ Recall that for an example like (15), the derivation for the "subject-result" reading is repeated as follows: In (16a), Zhangsan is the subject of the resultative de-clause, which activates the "subject-result" reading. The object NP is an independent syntactic object as in (16b). In (17b), the verb is copied from (16a) and merges with the object NP. The newly formed V-O combination then adjoins to the VP in (17a).

$\begin{array}{lllllll}\text { Zhangsan } & \text { qi } & \text { (na-pi) ma } & \text { qi } & \text { de } & \text { hen } & \text { lei. } \\ \text { Zhangsan } & \text { ride } & \text { that-CL horse } & \text { ride } & \text { DE } & \text { very } & \text { tired }\end{array}$
'Zhangsan rode (that horse) and became very tired.'
a. $\mathrm{K}=\left[_{\mathrm{VP}}\right.$ ride $\left[_{\text {deP }}\right.$
b. $\mathrm{L}=\left[_{\mathrm{NP}}\right.$ (that) horse $]$
de Zhangsan very tired ]]
a. $\mathrm{K}=\left[_{\mathrm{VP}}\right.$ ride $\left[_{\text {deP }}\right.$
de Zhangsan very tired ]]
b. $\mathrm{M}=\left[_{\mathrm{VP}}\right.$ ride $\left[{ }_{\mathrm{NP}}\right.$ (that) horse $\left.]\right]$

If the $\mathrm{V}-\mathrm{O}$ combination is higher than the modal as in (18), what we need is to have a ModalP merges with the original VP as in (19a). The newly formed V-O combination in (20b) adjoins to (20a) so that it is higher than the modal. In fact, the V-O combination in (18) can also be lower than the modal as in (21). In this example, the newly formed V-O combination can adjoin to the VP as in (15) before the modal merges with the structure.
Zhangsan qi (na-pi) ma yinggai/hui qi de hen lei. Zhangsan ride that-Cl horse should/can ride DE very tired 'Zhangsan should/would become tired after riding (that horse).'
a. $\mathrm{K}=\left[_{\text {ModalP }}\right.$ Modal $\left[_{\mathrm{VP}}\right.$ ride $\quad\left[_{d e \mathrm{P}}\right.$ de Zhangsan very tired ]] b. $\mathrm{L}=\left[\begin{array}{l}\mathrm{NP} \\ \text { (that) horse }]\end{array}\right.$

\footnotetext{
8 It should be noted here that the adjunction strategy discussed here is restricted within the TP domain. As pointed out by Cheng (2007), if the V-O combination is fronted to the CP domain as in (i), movement will be involved since island effects can be detected with a CNPC or an adjunct island in the sentence.
(i) Qi na-pi ma a, Zhangsan yinggai/keyi qi de hen lei. ride that-Cl horse EXCL Zhagnsan should/can ride DE very tired 'Zhangsan rode that horse and he should/would become very tired.' 
(20)

a. $\mathrm{K}=\left[\right.$ ModalP Modal $\left[\mathrm{VP}\right.$ ride $\left[_{\text {deP }}\right.$ de Zhangsan very tired $\left.]\right]$ b. $\mathrm{M}=\left[_{\mathrm{VP}}\right.$ ride $[\mathrm{NP}$ (that) horse $]$

(21) Zhangsan yinggai/hui qi (na-pi) ma qi de hen lei. Zhangsan should/can ride that-Cl horse ride DE very tired 'Zhangsan should/would become very tired after riding (that horse).'

At this point, recall that Hsu (2008) indicates that the V-O combination can never be lower than the BA NP (repeated here as (22)) and therefore concludes that the V-O combination has to be higher than $v$ P. However, I believe that the unavailability of the lower $\mathrm{V}-\mathrm{O}$ combination in (22) is only apparent. The example in (22) does not necessarily imply that the $\mathrm{V}-\mathrm{O}$ combination has to be higher than the $v \mathrm{P}$ domain.

(22) Zhangsan [xuanlian ma] ba ma [*xuanlian ma] xuanlian de hen lei. Zhangsan train horse BA horse train ma train DE verytired 'Zhangsan trained horses and the horses became very tired.'

For an example like (22), this is a BA construction and the "object-result" reading of the resultative $d e$-clause is available. Following Cheng (2007), the derivation for the "object-result" reading is shown in (23). The object NP undergoes movement from the resultative clause to Spec, VP in (23a) and (23b). The BA marker is merged at the $v$ head position. As one can see in (23c), VP adjunction following the BA NP is not possible since there is no VP boundary between the BA NP and the main verb. The only possible VP-adjunction position is to adjoin to VP after the object NP movement as shown in (23d). However, this adjunction is banned by a requirement of the BA construction itself: the adjacency requirement between BA and the BA NP. As pointed out by Huang, $\mathrm{Li}$ and $\mathrm{Li}$ (2009), the adjoined-manner adverbial in the BA construction has to precede BA or follow the BA NP as in (24a). The intervention of the adverbial between BA and the BA NP is simply not possible as in (24b).
a. $\left[{ }_{\mathrm{VP}}\right.$ train $\left[_{d e \mathrm{P}}\right.$ DE horse very tired ]]
b. $\left[{ }_{\mathrm{VP}}\right.$ horse $_{\mathrm{i}}$ train $\left[_{d e \mathrm{P}} \mathrm{DE} \mathrm{t}_{\mathrm{i}} \quad\right.$ very tired $\left.]\right]$
c. $\left[_{v \mathrm{P}}\right.$ Z. ba $\quad{ }_{\mathrm{VP}}$ horse $_{\mathrm{i}} \quad \operatorname{train}\left[{ }_{\text {dep }}\right.$ de $\mathrm{t}_{\mathrm{i}}$ very tired $\left.]\right]$
d. ${ }^{*}{ }_{v \mathrm{P}}$ Z. ba ${ }_{\mathrm{VP}}$ train horse $]\left[_{\mathrm{VP}}\right.$ horse ${ }_{\mathrm{i}}$ train $\left[_{d e \mathrm{P}}\right.$ de $\mathrm{t}_{\mathrm{i}}$ very tired $\left.\left.]\right]\right]$

(24) a. Zhangsan (hen quai) ba fan (hen quai) chi-wan-le. Zhangsan very quickly BA rice very quickly eat-finish-Asp

'Zhangsan finished eating quickly.'

b. Zhangsan ba (*hen quai) fan chi-wan-le. Zhangsan BA very quick rice eat-finish-Asp

Hsu (2008) adopts Li's (2006) analysis for the BA construction, hence an independent $B a \mathrm{P}$ is merged into the structure right above $v \mathrm{P}$ as in (25). It is indeed possible for the $\mathrm{V}-\mathrm{O}$ combination to adjoin to $\mathrm{VP}$ and lower than the BA NP in (25). An impossible word order then is derived. 
$\left[{ }_{B a \mathrm{P}}\right.$ Z. ba $\left[_{v \mathrm{P}}\right.$ horse $_{\mathrm{i}}\left[_{\mathrm{V}-\mathrm{O}}\right.$ train horse $]\left[_{\mathrm{VP}} \mathrm{t}_{\mathrm{i}}\right.$ train $\left[_{d e \mathrm{P}}\right.$ de $\mathrm{t}_{\mathrm{i}}$ very tired $\left.\left.\left.]\right]\right]\right]$

However, as one can see, this VP-adjunction is only possible under Li's (2006) analysis for the BA construction, but not under Cheng's original analysis for the BA construction. The validity of this argument seems problematic. In addition, I will show that although structurally VP-adjunction of the V-O combination is possible in (25), it can still be excluded by another reason independently. To do that, I will need to discuss the property of the object NP in the V-O combination.

\subsection{The object NP}

In the previous section, I discussed the first puzzle and presented a solution. That is, the $\mathrm{V}-\mathrm{O}$ combination may adjoin to any projection between the VP periphery and TP. Interestingly, this range seems to provide us with a good clue to solve the second puzzle. In line with Hsu (2008), I propose that the object NP in the V-O combination is an internal topic. However, unlike Hsu who proposes for a TopicP in the TP domain, I believe that the syntactic position of the object NP itself marks its internal topicalization automatically.

For a typical Mandarin SVO example (26a), Tang (1990) shows that the object NP can be externally topicalized as in (26b). Later it is also proposed in Paul $(2002,2005)$ that the object NP can be internally topicalized to the TP domain as in $(26 \mathrm{c})$.
a. Zhangsan
kan-wan-le
zhe-ben shu.
Zhangsan read-finish-Asp this-Cl book
'Zhangsan finished reading this book.'
b. Zhe-ben shu,
Zhangsan
kan-wan-le
this-Cl book Zhangsan read-finish-Asp
c. Zhangsan
zhe-ben shu kan-wan-le. Zhangsan this-Cl book read-finish-Asp

The properties of internal topicalization of the object NP in the resultative declause of the verb copying construction explains the indefinite NP difference naturally as discussed in Section 2. Recall that in the resultative de-clause, an indefinite NP like (27a) is acceptable, while an indefinite NP with a numeral and a classifier is not (repeated here as (27b)). This kind of contrast, in fact, is quite wellknown in the case of external topicalization as shown in (28) ( $\mathrm{Li}$ and Thompson 1981, Liu 1997, Bender 2000 and many others).
a. Zhangsan
qi ma
qi
de hen
lei.
Zhangsan
ride horse ride
DE very
tired
'Zhangsan rode and became very tired.'
b. *Zhangsan qi yi-pi ma qi de hen lei.
Zhangsan ride one-Cl horse ride DE very tired
'Zhangsan rode a horse and became very tired.' 

a. Gou, Zhangsan hen xihuan. dog Zhangsan very like
'Zhangsan likes dogs very much.'
b. *Yi-zhi gou, Zhangsan hen xihuan. one-Cl dog Zhangsan very like 'Zhangsan likes a dog very much.'

As first mentioned in Tsai (1995), the same pattern is also observed in the internal topicalization case of example (26a) as in (29).
a. Zhangsan
shu kan-wan-le.
Zhangsan
book read-finish-Asp
'Zhangsan finished reading the book.'
b. *Zhangsan yi-ben shu kan-wan-le.
Zhangsan one-Cl book read-finish-Asp
'Zhangsan finished reading a book.'

When the indefinite NP is a generic bare noun without a bare numeral determiner (i.e. it is not a NP with a bare numeral determiner), it can undergo topicalization externally or internally. If the object NP in the V-O combination is also a case of internal topicalization, the contrast between (27a) and (27b) is expected. Recall that the proposal in Section 3.1 allows both indefinite and definite object to be merged in the initial structure and adjoin freely from the VP periphery to the TP domain. The ungrammaticality of (27b) is simply because an indefinite NP with a bare numeral determiner is not allowed to be an internal topic.

Moreover, the topic property of the object NP also explains why the V-O combination can never be lower than the BA NP even if a different analysis for the BA construction is adopted. The relevant example is repeated here as (30). Recall that Hsu (2008) adopts Li's (2006) analysis for the BA construction and predicts that the VP-adjoined V-O combination under Cheng's analysis can be lower than the BA NP in structure (31), which is contrary to the fact. Therefore, Hsu (2008) rejects Cheng's (2007) analysis and proposes a TopicP in the TP domain instead.

(30) Zhangsan [xuanlian ma] ba ma [*xuanlian ma] xuanlian de hen lei. Zhangsan train horse BA horse train horse train DE very tired 'Zhangsan trained horses and the horses became tired.'

(31) $\left[_{B a \mathrm{P}}\right.$ Z. ba $\left[_{v \mathrm{P}}\right.$ horse $_{\mathrm{i}}\left[_{\mathrm{V}-\mathrm{O}}\right.$ train horse $]\left[_{\mathrm{VP}} \mathrm{t}_{\mathrm{i}}\right.$ train $\left[_{d e \mathrm{P}}\right.$ de $\mathrm{t}_{\mathrm{i}}$ very tired $\left.\left.]\right]\right]$

However, if the object NP in the V-O combination is considered as an internal topic as proposed above, structure (31) can be ruled out via the order of topics in the information structure. In the literature for external topics, there are three different kinds of topics proposed: Aboutness Topic (base-generated topic), Hanging Topic (based generated topic coindexed with a resumptive pronoun), and Left Dislocation (a moved topic). According to Badan and Del Gobbo (2007) and 
Del Gobbo \& Badan (2007), a certain order among them must be obeyed as shown in (32). An example containing all three external topics is cited in (33).

(32) Aboutness Topic $>$ Hanging Topic $>$ Left Dislocation $>$ lian-Focus $>$ TP

(33) Wo de jiaren, baba, cong na-jia yinhang, wo yijing ti/wei ta jiedao I DE family father from that-Cl bank I already for him borrow hen duo qian le. very much money Asp

'As for my family, my father, from that bank, I already borrowed a lot of money for him.'

(Badan and Del Gobbo 2007)

Under Cheng's sideward movement analysis, the object NP (with the copied verb) is merged to the structure directly. Hence, it can be categorized as a basegenerated topic. ${ }^{9}$ On the other hand, the BA NP in the BA construction is also a kind of internal topic as discussed and proposed by Tsao (1987a). However, the BA NP in (31) is derived by movement. Assuming that the fixed order among external topics is also available for internal topics, we then can explain why the $\mathrm{V}-\mathrm{O}$ combination has to precede the BA NP rather than following it as in (30). Although structurally it is possible to have the derivation as in (31), the fixed order between base-generated topic and the moved topic will rule this structure out as predicted.

Note that although the current proposal also involves internal topicalization, it differs from Hsu's (2008) proposal in two major respects. First of all, there is no Topic projection needed. As one can see, in Mandarin Chinese, the external topic is in the CP domain, while the internal topic is between the VP periphery and the TP domain. Importantly, I would like to propose that in Mandarin, as long as the object NP is not located in the VP complement position (i.e. the standard object position), it is interpreted as a Topic in the information structure by following the mapping theory by Heycock (1993) and (2007) for Japanese, and Neeleman and van de Koot (2008) for Dutch. ${ }^{10}$ It is not necessary that a topic is always bound with a Topic projection. This inference is also supported by the BA construction. As mentioned above, the BA NP is also a kind of internal topic by Tsao (1987a). Note that in the previous discussion, there is no Topic projection to host the BA NP independently under either Cheng's proposal or Li's (2006) proposal for the BA construction. The salience of the BA NP position shows that it is different from the typical object NP in the complement position and

9 Recall that Hsu (2008) also proposes that the V-O combination is a base-generated topic, located in the Topic Projection in the TP domain.

10 Unlike the cartographic approach, the mapping approach does not posit Topic or Focus projections, which means that Topicalization/Focalization are not driven by Topic/Focus feature checking. The mapping approach also does not order the two in the syntax. The output of the syntax is simply mapped into information structure via mapping rules such as Comment Mapping Rule and Background mapping rule as proposed in Neeleman and van de Koot (2008). 
can be interpreted as a topic. If we accept this line of reasoning, then it is not surprising that the object NP in the V-O combination can be interpreted as an internal topic. The syntactic position ranging from the VP-adjoined position to the TP domain then makes the object NP to be interpreted as a topic in the verb copying construction.

The second difference between the current proposal and Hsu's (2008) proposal lies in what is interpreted as a topic. I discuss this difference in the following section.

\subsection{The copied verb}

Recall that Cheng (2007) proposes that a VP constituent is formed when the copied verb merges with the object NP independently. However, in the previous section, I propose that the object NP in the $\mathrm{V}-\mathrm{O}$ combination is interpreted as a topic. This is different from Hsu's proposal in which the whole VP is interpreted as a topic. The current proposal then implies that the "VP" (the V-O combination) has something different other than the ordinary VPs. And I believe the difference lies in the copied verb itself.

Indeed, the copied verb in the $\mathrm{V}-\mathrm{O}$ combination does exhibit some intriguing properties. First of all, in Tsao (1987b), he has shown that the copied verb does not behave as a typical verb. It cannot take an aspect marker or form an A-not-A question as in (34) and (35) respectively.

(34)a. Zhangsan qi-le/zhe/guo ma.

Zhangsan ride-Asp horse

'Zhangsan rode/is riding a horse.'

b. *Zhangsan qi-le/zhe/guo ma qi-de hen lei.

Zhangsan ride-Asp horse ride-DE very tired

(35)a. Zhangsan qi-bu-qi ma?

Zhangsan ride-not-ride horse

'Does Zhangsan ride horses?'

b. *Zhangsan qi-bu-qi ma qi-de hen lei?

Zhangsan ride-not-ridehorse ride-DE very tired

Moreover, in Section 2, we have seen that the copied verb can be omitted when the following object is [-human]. The optionality also implies that the copied verb is not a typical verb since a typical verb cannot be omitted randomly. Therefore, instead of considering the copied verb as a verb, I propose that the copied verb is a kind of differential object marking, as discussed in Bossong (1985) and Aissen (2003). ${ }^{11}$

11 Under the framework of bare phrase structure, the copied merges with the object NP as a V-O combination, and the label for the newly formed phrase is not the copied verb as the usual VP. The label here is assumed to be the object NP since the phrase exhibits internal topic properties and the copied verb can be omitted. 
It is well-known that differential object marking across languages is sensitive to the definiteness or animacy of the object. For example, in Spanish, an obligatory preposition $a$ has to emerge right before the [+animate] object, but is absent when the object is [-animate] as in (36).
a. John ama le libros. (Spanish)
John likes the books
'John likes the books.'
b. John ama *(a) Mary
John likes Mary
'John likes Mary.'

Rodríguez-Mondoñedo (2007) observes that this DOM in Spanish $a$ is sensitive to [+animate] and [+definite] object NPs. This can be found in Romanian and Hindi as well. Other DOMs such as the one in Malayalam is only sensitive to [+animate] object NPs, while DOM in Hebrew is only sensitive to [+definite] object NPs.

Moreover, as pointed out by van Bergen (2006), some DOM languages also differ in defining what counts as definiteness or animacy for the DOM. The universal prominence scales of definiteness and animacy is shown in (37) and (38).

(37) Definiteness scale: Pronoun $>$ Proper Noun $>$ Definite NP $>$ Indefinite Specific NP $>$ Indefinite Non-specific NP

Animacy scale: Human > Animate > Inanimate

In some languages, only [+human] receives DOM, while non-human objects (animate and inanimate) do not. Hence languages may also differ in where they make the split on the scale for the DOM. Apparently, in the following discussion, we will see that Mandarin does differ from Spanish in the respect of choosing what counts as "animacy".

The phenomenon that the preposition $a$ in Spanish is sensitive to the [ \pm animacy] of object NPs is reminiscent of the [ \pm human] restriction observed in the resultative $d e$-clause of the verb copying construction. Recall that the copied verb is obligatory for [+human] object NPs, but is optional for [-human] object NPs, repeated here as (39) and (40).

$\begin{array}{llllllll}\text { Zhangsan } & \text { (da) } & \text { na-pi } & \text { ma } & \text { da } & \text { de } & \text { hen } & \text { lei. } \\ \text { Zhangsan } & \text { hit } & \text { that-Cl } & \text { horse } & \text { hit } & \text { DE } & \text { very } & \text { tired }\end{array}$

'Zhangsan hit that horse and became very tired.'

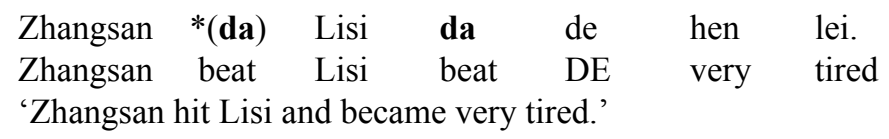


Two salient differences between the DOM in Spanish and Mandarin then emerge. First, these two languages make different choices on what counts as "animacy". In Spanish, the "animacy" split is between [+animate] and [-animate] objects. However, in Mandarin, the splits falls between [+human] (i.e. [+animate]) and [human] (i.e. [-animate]). Second, the appearance of the DOM is also different. In Spanish, the absence of the DOM for [-animate] object NPs is obligatory. However, the DOM for [-human]/[-animate] object NPs in Mandarin is optional. This is not surprising, though, since DOM varies a lot across languages. In addition, the DOM pattern in the resultative de-clause of the verb copying construction is similar to the one observed in Kannada, which is also a DOM language. Kannada is a language spoken in India, and its [+human] object NPs have to be marked by DOMs. Other [-human] objects can be all unmarked, but they can be optionally marked by DOMs if they are specific (see Rodríguez-Mondoñedo 2007). In (40), the [+human] object has to be preceded by the copied verb. The object NP in example (39) is inanimate and definite, hence a DOM is optional. ${ }^{12}$

The proposal that the copied verb is a DOM is also supported by the BA construction in Mandarin. van Bergen (2006) and Yang and van Bergen (2007) have proposed that BA is also a kind of DOM in Mandarin. The following examples (41) and (42) exhibit a similar pattern that we have observed in the resultative de-clause. That is, if BA is omitted in (42), Lisi cannot be interpreted as the object but has to be interpreted as the subject instead.

Zhangsan ba na-pi ma da-le yi-duan.
Zhangsan BA that-Cl horse hit-Asp once
'Zhangsan beat that horse once.'

\begin{tabular}{|c|c|c|c|c|}
\hline Zhangsan & $*(\mathrm{ba})$ & Lisi & da-le & yi-duan. \\
\hline Zhangsan & BA & Lisi & hit-Asp & once \\
\hline
\end{tabular}

Moreover, the DOM mechanism has been proposed to be related to topical objects in the literature (see García García 2005 for Spanish, Guntsetseg 2008 for Mongolian, Dalrymple and Nikolaeva 2011 for Tundra Nenets (Uralic) and Tigre). I have shown that the object NP in the resultative de-clause involves internal topicalization. The current analysis hence provides more supporting evidence to this proposal which relates differential object marking to internal topicalization. ${ }^{13}$

\footnotetext{
12 There is still a slight difference between Kannada and Mandarin. For an inanimate and generic indefinite NP, the DOM is still optional, which may be noted as a special DOM property in Mandarin Chinese.

13 As discussed in section 3.2, the BA construction also involves internal topicalization as proposed by Tsao (1987a). The correlation between DOM and internal topicalization in Mandarin Chinese can be further strengthened by the BA construction as well.
} 
Lastly, the current proposal can differentiate the current object NP topic proposal from the VP topic proposal as in Hsu (2008). A resultative de-clause counterpart of a double object construction (43) can be constructed as in (44). ${ }^{14}$ The adverbial ye ('also') marks the $v \mathrm{P}$ periphery (Shyu 1995), which indicates that a VP containing the copied verb, the indirect object and the direct object is in the TP domain. However, a sentential adverbial xianran ('apparently') between the IO and the DO shows that the DO is not inside the VP. Under Hsu's (2008) analysis, the VP containing the copied verb and the IO can be base-generated as a topic, and the DO as a focus in the TP domain, following the topic $>$ focus order as discussed in Hsu (2008).

$\begin{array}{lllll}\text { Zhangsan } & \text { song } & \text { Lisi } & \text { (zhe-)yi-fen } & \text { liwu. } \\ \text { Zhangsan } & \text { give } & \text { Lisi } & \text { this-one- Cl } & \text { present }\end{array}$

'Zhangsan gave Lisi a/this present.'

$\begin{array}{lllll}\begin{array}{l}\text { Zhangsan } \\ \text { Zhangsan }\end{array} & \begin{array}{c}{ }_{\mathrm{VP}} \text { song Lisi] } \\ \text { give Lisi }\end{array} & \begin{array}{l}\text { (xianran) } \\ \text { apparently this-one- } \mathrm{Cl}\end{array} & \begin{array}{l}\text { zhesent } \\ \text { present }\end{array} \\ \text { song } & {[\mathrm{de} \quad \text { hen }} & \text { tongku]. } & \\ \text { give } & \text { DE } \quad \text { very } & \text { suffering } & \\ \text { 'Zhangsan apparently also suffered from giving Lisi this present.' }\end{array}$

However, it then becomes a puzzle why example (44) is grammatical while example (45) is ungrammatical. The only difference between (44) and (45) lies in the indirect object in the base-generated topic VP.

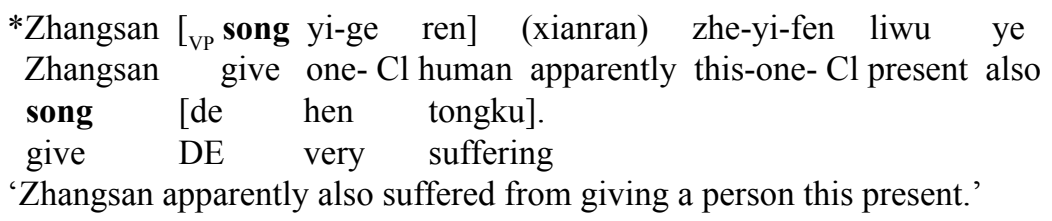

Under the current proposal, the ungrammaticality of (45) is expected because indefinite NPs with bare numeral determiners cannot be internal topics as discussed above. Therefore, although Hsu's analysis also involves internal topicalization, I conclude that it is not possible that the whole VP is interpreted as a topic as proposed.

To summarize, in this section, I have extended Cheng's (2007) proposal for the "subject-reading" of the resultative de-clause and clarify the nature of the V-O combination. The V-O combination may adjoin to any projection freely from the VP periphery to the TP domain. The object NP as a case of internal topicalization also explains that its location may range from the VP-adjoined position to the TP domain. The acceptability of bare indefinite NPs is also a consequence of internal

14 A similar example can be found in footnote 11 in Hsu (2008). 
topicalization. On the other hand, the copied verb as a case of DOM then explains the optional/obligatory emergence of the copied verb preceding the object NP.

\section{The manner de-clause}

Cheng (2007) also discusses the manner de-clause of the verb copying construction as shown in (46). Different from the complementary resultative deP clause in (1), the $d e \mathrm{P}$ in (46) is considered an adverbial clause in the following example.

$\begin{array}{llllll}\text { Zhangsan qi na-pi ma qi } & \text { de } & \text { hen } & \text { kuai. } \\ \text { Zhangsan ride that-Cl horse } & \text { ride } & \text { DE } & \text { very } & \text { quick } \\ \text { 'Zhangsan rode that horse very fast.' } & & & & \end{array}$

Following Huang (1988) who argues that the manner adverbial de-clause is an secondary predicate/inner adverbial, the VP structure for (46) proposed by Cheng (2007) is shown in (47). The object is in the outer object position.

$\left[\mathrm{VP}\right.$ that horse ride $\left[_{d e \mathrm{P}}\right.$ de very fast $\left.]\right]$

The verb in (47) undergoes movement to the $v$ head position, and post-syntactically the original copy is fused with the de-clause. The fusion allows the simultaneous spell-out of the two copies of the verb since now they are distinct and can be linearized according to LCA as in (48).

$$
\left[_ { v \mathrm { P } } \text { ride } \quad \left[_{\mathrm{VP}} \text { that horse ride }-d e\right.\right. \text { very fast }
$$

The derivation in (48) is not the only derivation for the manner de-clause, though. Cheng (2007), in fact, proposes two different derivations for the manner de-clause of the verb copying construction. The specificity of the object NP determines the corresponding derivation needed. Following Diesing (1992) and Marantz (1993), Cheng assumes that the Spec, VP position can only host specific nouns. The object NP in (46) is a definite one and therefore is able to be located at the Spec, VP position. However, a generic indefinite NP following the copied verb is also allowed in the manner $d e$-clause of the verb construction as shown in (49). For such a grammatical example with a generic indefinite NP like (49), Cheng suggests that this case can be derived via sideward movement as the "subject-result" reading of the resultative de-clause. As shown in (50), the indefinite generic NP merges with the copied verb. The newly-formed VP constituent then adjoins to the original VP.

$\begin{array}{lllllll}\text { Zhangsan } & \text { qi } & \text { ma } & \text { qi } & \text { de } & \text { hen } & \text { kuai. } \\ \text { Zhangsan } & \text { ride } & \text { horse } & \text { ride } & \text { DE } & \text { very } & \text { quick }\end{array}$

'Zhangsan rode the horse very fast.'

(50) $\left[_{\mathrm{TP}}\right.$ Zhangsan $\left[_{\mathrm{VP}}\right.$ ride horse $]\left[_{\mathrm{VP}}\right.$ ride $\left[_{d e \mathrm{P}} d e\right.$ very fast $\left.]\right]$ 
Although there is no ambiguity observed as in the resultative de-clause, both standard movement and sideward movement are still needed for the manner declause of the verb copying construction. The standard movement is for the definite object NP (example (46)), while the sideward movement is required by the generic indefinite object NP (example (49)).

As one can see in Cheng (2007), there are two independent reasons why Spec, VP is not available in the verb copying construction: ergative structure (for the "subject-result" reading in the resultative de-clause) or this assumption that the Spec, VP position can only host specific NP. However, as pointed out by Tieu (2009), what is important in the manner de-clause is the fusion between the main verb and the $d e$-clause. Essentially, unlike the resultative $d e$-clause, there is only one single interpretation observed in the manner de-clause of the verb copying construction. That is, the manner $d e$-clause always modifies the riding event, no matter the object NP is interpreted definitely or generically. A standard movement analysis can be adopted for both definite and indefinite object NPs if there is no such assumption that indefinite object NPs cannot occupy Spec, VP. ${ }^{15}$ Moreover, we, in fact, can construct a BA construction counterpart of the manner de-clause with a generic indefinite NP in example (51), and it is grammatical. ${ }^{16}$

$\begin{array}{llllll}\text { Zhangsan zuoshi ba ma qi } & \text { de } & \text { hen } & \text { kuai. } \\ \text { Zhangsan always } & \text { BA horse ride } & \text { DE } & \text { very } & \text { fast } \\ \text { 'Zhangsan always rides horses very fast.' } & & & \end{array}$

Following the analysis for the formation of the BA construction by Cheng (2007), the BA NP is located at Spec, VP. This then means that the generic indefinite NP $m a$ ('horse') is at Spec, VP in (51). Hence the assumption that Spec, VP cannot host indefinite objects seems to be problematic.

Putting all the discussions together, I believe that the current analysis for the resultative $d e$-clause can be applied to the manner $d e$-clause as well. In line with Tieu (2009), there is no need to distinguish definite object NPs from generic indefinite object NPs. Hence, we do not need both sideward movement and standard movement for different object NPs in the manner de-clause of the verb

15 It should be noted that what I have adopted from Tieu (2009) is her point of view for the manner de-clause of the verb copying construction only. In her paper, the final conclusion is that both sideward movement and the standard movement are both needed if all subtypes of the verb copying construction are considered.

16 A resultative de-clause counterpart of example (51) is also available as illustrated below. This further shows that Spec, VP indeed can host indefinite NPs.

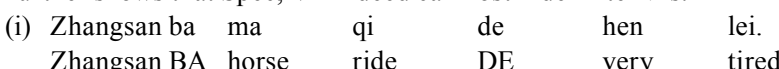

'Zhangsan rode the horse and the horse became tired.' 
copying constructions.${ }^{17}$ However, different from Tieu (2009), I propose that it is sideward movement, but not standard movement, that is needed for the manner declause of the verb copying construction. This is because if the standard movement is involved, the object NP and the copied verb will not form a constituent as in (48). As shown in Cheng (2007), only the "subject-result" reading, and not the "objectresult" reading, of the de-resultative clause is available when the copied verb and the object NP are externally topicalized as in (52). This is because what has been topicalized has to be a constituent, which is only available via sideward movement.
Qi na-pi ma a, Zhangsan qi de hen lei. ride that-Cl horse EXCL Zhangsan ride DE very tired 'Zhangsan rode that horse and he became very tired.'

Interestingly, for the manner $d e$-clause, we do find the following grammatical example (53) where the copied verb and the object NP are externally topicalized.

$\begin{array}{lllllll}\text { Qi na-pi ma a, } & \text { Zhangsan } & \text { qi de } & \text { hen } & \text { kuai. } \\ \text { ride that-Cl horse EXCL Zhangsan } & \text { ride } & \text { DE } & \text { very } & \text { fast } \\ \text { 'Zhangsan rode that horse very fast.' } & & & & \end{array}$

Hence, a standard movement analysis seems not to be applicable for the manner $d e$-clause. On the other hand, if the sideward movement is involved in the manner $d e$-clause, we expect to find some similar phenomena in the structure which are observed in the "subject-result" reading of the de-clause. In addition, following the current proposal, the sideward movement in the manner $d e$-clause should also involve both internal topicalization and differential object marking.

Indeed, we can see that the pattern observed in the "subject-reading" for the resultative $d e$-clause is detectable in the manner $d e$-clause as well. The V-O combination can be higher than the modals as in (54).$^{18}$ The object NP cannot be an indefinite NP with a bare numeral determiner as in (55). And the contrast between [-human] and [+human] object NP is shown in (56).
Zhangsan qi (na-pi) ma yinggai/keyi qi
de hen
kuai.
Zhangsan ride that- $\mathrm{Cl}$ horse should/can ride $\mathrm{DE}$ very fast
'Zhangsan should/can ride (that horse) very fast.'

$\begin{array}{llllll}\text { *Zhangsan qi yi-pi ma } & \text { qi } & \text { de } & \text { hen } & \text { kuai. } \\ \text { Zhangsan ride one- } \mathrm{Cl} \text { horse } & \text { ride } & \text { DE } & \text { very } & \text { quick } \\ \text { 'Zhangsan rode a horse very fast.' } & & & & \end{array}$

\footnotetext{
17 Note that the point here is to say that when we have a "verb copying" construction for the manner de-clause, only the sideward movement is needed. There is no need to have both sideward movement and standard movement for generic indefinite object NPs and specific object NPs, respectively. But for the BA counterpart of the manner de-clause as the one in (51), the standard movement is still needed to construct a BA construction as proposed by Cheng (2007).

18 Example (54) again shows that standard movement is not involved in the manner de-clause of the verb copying construction since under the standard movement analysis, the copied verb and the object NP have to be located inside the $v \mathrm{P}$ domain and cannot be possibly higher than the modal.
} 


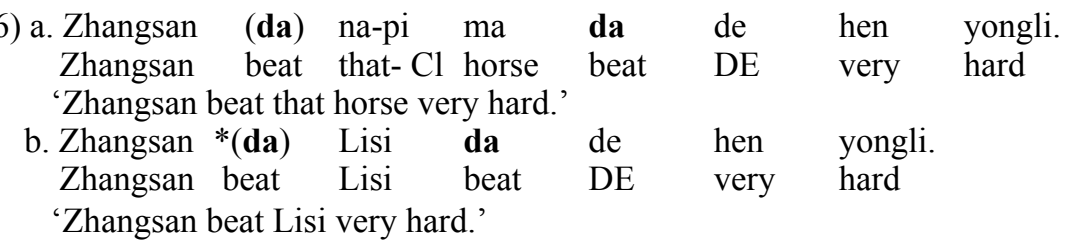

Following the sideward movement for the resultative de-clause, the derivation for the manner $d e$-clause is shown from (57) to (59). The manner $d e$-clause merges with the verb in (57a). In (58a), the verb is copied and merges with the object NP in (57b) independently and forms (58b). The newly formed V-O combination adjoins to the VP as in (59).
a. $\mathrm{K}=\left[\mathrm{VP}\right.$ ride $\left[{ }_{d e \mathrm{P}}\right.$ de very fast $\left.]\right]$
b. $\mathrm{L}=\left[_{\mathrm{NP}}\right.$ (that) horse $]$

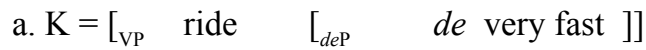
b. $M=\left[_{V P}\right.$ ride $\left[{ }_{N P}\right.$ (that) horse $\left.]\right]$

$$
\left[\left[_{\mathrm{VP}} \text { ride }\left[_{\mathrm{NP}} \text { (that) horse }\right]\left[_{\mathrm{VP}} \text { ride } \quad\left[_{\text {deP }} \quad \text { de very fast }\right]\right]\right]\right.
$$

Recall that the adjunction position of the V-O combination may range from VP periphery to the TP domain. ${ }^{19}$ Therefore, the $\mathrm{V}-\mathrm{O}$ combination can be higher than the modal in (54). And since the object NP is interpreted as an internal topic inside the TP domain, an indefinite object NP with a bare numeral determiner in (55) is not allowed. Finally, the [ \pm human] difference in (56) can be explained if the copied verb is interpreted as a kind of differential object marking.

\section{Conclusion}

In this paper, I discuss the components involved in the sideward movement proposed by Cheng (2007). I first re-examine the proposed derivations involved in the "subject-result" reading of the resultative de-clause of the verb copying construction as proposed by Cheng (2007). I have shown that there are some facts/

\footnotetext{
19 One may wonder whether the copied verb appearing other than in the VP-adjoined position violates the Phase Impenetrability Condition [PIC] by Chomsky $(2000,2001$, and 2004) in the manner $d e$-clause of the verb copying construction. For the "subject-result" reading of the resultative $d e$ clause, there is no problem like this since there is no $v \mathrm{P}$ presented in the structure. However, for the manner $d e$-clause, a phase $v \mathrm{P}$ is presented. If the VP complement is sent to PF, it may be argued that the copying of the verb is not possible in the TP domain. However, if we follow Bošković's (2007) paraphrase for PIC, the copying of the verb is still allowed even if $v \mathrm{P}$ is a phase. Bošković (2007) discusses several cases with languages that allow agreement to reach into a finite $\mathrm{CP}$, such as in Chukchee, Blackfoot, and Alutor. He argues that the PIC is a PF constrain. This then shows that phases are not syntactic opaque domains, though the PIC eventually forces successive cyclic movements syntactically because of it being a phonological consideration. Hence under this version of phases, phases are still accessible from the outside in the syntax. In examples of the manner declause where the derivation has reached $v \mathrm{P}$ or other higher domains, the main verb can still be copied and merges with the object NP via sideward movement as proposed by Cheng (2007).
} 
puzzles that need to be considered regarding the resultative de-clause. Extending Cheng's (2007) proposal, I show that the adjunction of the copied verb and the object NP can range from the VP periphery to the TP domain. Moreover, I show that properties shown by the object NP and the copied verb are natural consequences of two common syntactic mechanisms employed in Mandarin Chinese. The object NP between the VP periphery and the TP domain is a case of internal topicalization, which then explains why the object NP can be higher than modals and cannot be indefinite NPs with a bare numeral determiner. The copied verb is a case of DOM as in the BA construction, which is also widely observable in other natural languages. The current analysis is also applicable to the manner $d e$-clause of the verb copying construction, in which I have shown that only sideward movement is needed for the necessary derivation.

\section{Acknowledgments}

This paper is part of my research sponsored by the National Science Council, Taiwan (Grant No. NSC 102-2410-H-415-010). I hereby acknowledge the financial support of the NSC. I would also like to thank the two anonymous reviewers for their valuable comments and suggestions on the previous version of this paper. The current version could not have been accomplished without their insightful reviews. All errors remain mine.

\section{References}

Aissen, Judith. 2003. Differential object marking: Iconicity vs. economy. Natural Language \& Linguistic Theory 213. 435-448.

Badan, Linda and Francesca Del Gobbo. 2007. On the Syntax of Topic and Focus and Chinese. Ms. Università di Padova e Unviesità Ca' Foscari, Venezia.

Bošković, Željko. 2007. Agree, phases, and intervention effects. Linguistic Analysis 33. 54-96.

Bender, Emily. 2000. The syntax of Mandarin BA: Reconsidering the verbal analysis. Journal of East Asian Linguistics 9(2). 105-145.

Bossong, Georg. 1985. Empirische universalienforschung. Differentielle objektmarkierung in der neuiranischen sprachen. Tübingen: Narr.

Cheng, Lisa Lai-Shen. 2007. Verb copying in Mandarin Chinese. In Corver, Norbert \& Jairo Nunes (eds.), The Copy theory of movement, 151-174. Utrecht: Utrecht University.

Chomsky, Noam. 1995. The minimalist program. Cambridge, MA: The MIT Pass.

Chomsky, Noam. 2000. Minimalist inquiries: The framework. In Roger Martin, David Michaels \& Juan Uriagereka (eds.), Step by step: Essays on minimalism in honor of Howard Lasnik, 89-155. Cambridge: The MIT Pass.

Chomsky, Noam. 2001. Derivation by phase. In Michael Kenstowicz (ed.), Ken Hale: A life in language, 1- 52. Cambridge, Mass: The MIT Pass.

Chomsky, Noam 2004. Beyond explanatory adequacy. In Adriana Belletti (ed.), Structures and beyond: The cartography of syntactic structure 3, 104-131. Oxford: Oxford University Press. 
Dalrymple, Mary \& Irna Nikolaeva. 2011. Objects and information structure. Massachusetts: Cambridge University Press.

Del Gobbo, Francesca \& Linda Badan. 2007. On the syntax of topic and focus and Chinese. Paper presented at the 81th Linguistic Society of America Annual Meeting. 4-7 January.

Diesing, Molly. 1992. Indefinites. Cambridge, MA: The MIT Pass.

Fang, Ji \& Peter Sells. 2007. A formal analysis of the verb copy construction in Chinese. In Tracy Holloway King \& Miriam Butt (eds.), Proceedings of the LFG07 conference, 198-213. Stanford, California: CSLI Publications.

García García, Marco. 2005. Differential object marking and informativeness. In Klaus von Heusinger, Georg A. Kaiser \& Elisabeth Stark (eds.), Proceedings of the Workshop "Specificity and the evolution emergence of nominal determination systems in romance”, Arbeitspapier 119, 17-31. Konstanz: Universität Konstanz.

Gouguet, Jules. 2006. Adverbials and Mandarin argument structure. In Oliver Bonami \& Patricia Cabredo Hofherr (eds.), Empirical issues in syntax and semantics 6, 155-173. Strasbourg : CNRS.

Guntsetseg, Dolgor. 2009. Differential object marking in (Khalkha-)Mongolian. In Ryosuke Shibagaki \& Reiko Vermeulen (eds.), MIT Working Papers in Linguistics (MWPL) 58, Proceedings of the 5th Workshop on Formal Altaic Linguistics (WAFL 5), 115-129. Cambridge, Mass: MIT Working Papers in Linguistics/MITWPL.

Halle, Morris. 1997. Distributed morphology: Impoverishment and fission. In Benjamin Bruening, Yoonjung Kang \& Maureen McGinnis (eds.), MITWPL 30: Papers at the Interface, 425-449. Cambridge: MITWPL.

Halle, Morris \& Alec Marantz. 1993. Distributed morphology and the pieces of inflection. In Ken Hale and Samuel Jay Keyser (eds.), The View from Building 20: Essays in honor of Sylvain Bromberger, 111-176. Cambridge: MIT Press.

Halle, Morris and Alec Marantz. 1994. Some Key Features of Distributed Morphology. In Andrew Carnie \& Heidi Harley with Tony Bures (eds.), 275-288. MITWPL 21: Papers in Phonology and Morphology.

Heycock, Caroline. 1993. Syntactic predication in Japanese. Journal of East Asian Linguistics 2(2). 167-211.

Heycock, Caroline. 2007. Japanese -wa, -ga, and information structure. In Shigeru Miyagawa \& Mamoru Saito (eds.), The Oxford Handbook of Japanese linguistics, 54-83. New York: Oxford University Press.

Hoekstra, Teun and René Mulder. 1990. Unergatives as copular verbs: Locational and existential predication. The Linguistic Review 7(1). 1-79.

Hsu, Yu-Yin. 2008. The sentence-internal topic and focus in Chinese. In Marjorie K.M. Chan and Hana Kang (eds.), Proceedings of the 20th North American Conference on Chinese Linguistics (NACCL-20), 635-652. Columbus, Ohio: The Ohio State University.

Huang, C.-T. James. 1982. Logical relations in Chinese and the theory of grammar. Cambridge : Massachusetts Institute of Technology dissertation.

Huang, C.-T. James. 1984. On the distribution and reference of empty pronouns. 
Linguistic Inquiry 15. 531-574.

Huang, C.-T. James. 1988. Wo pao de kuai and Chinese phrase structure. Language 64. 274-311.

Huang, C.-T. James. 1997. On lexical structure and syntactic projection. Chinese Languages and Linguistics 3. 45-89.

Huang, C.-T. James, Audrey Li \& Yafei Li. 2009. The syntax of Chinese. Cambridge: Cambridge University Press.

Kayne, Richard. 1994. The antisymmetry of syntax. Cambridge, MA: The MIT Press.

Li, Charles N. \& Sandra Annear Thompson. 1981. Mandarin Chinese: A functional reference grammar. Berkeley, Los Angeles \& London: University of California Press.

Li, Yen-Hui Audrey. 2006. Chinese ba. In Martin Everaert \& Henk van Riemsdijk (eds.), The Blackwell companion to syntax. Vol. 1, 374-468. Malden, MA: Blackwell Publishing.

Lin, T.-H. Jonah. 2001. Light verb syntax and the theory of phrase structure. Irvine: University of California dissertation.

Liu, Feng-Hsi. 1997. An aspectual analysis of Ba. Journal of East Asian Linguistics 6. 51-99.

Lu, Hui-Chuan.1994. Preverbal NPs in Spanish and Chinese. Los Angeles: University of California dissertation.

Marantz, Alec. 1993. Implications of asymmetries in double object constructions. In Sam A. Mchombo (ed.), Theoretical aspects of Bantu grammar 1, 113-150. Stanford, CA: Center for the Study of Language and Information (CSLI).

Neeleman, Ad \& Hans van de Koot. 2008. Dutch scrambling and the nature of discourse templates. Journal of Comparative Germanic Linguistics 11(2). 137189.

Nunes, Jairo. 2001. Sideward movement. Linguistic Inquiry 31(2). 303-344.

Nunes, Jairo. 2004. Linearization of chains and sideward movement. Cambridge, MA: The MIT Press.

Paul, Waltraud. 2002. Sentence-internal topics in Mandarin Chinese: the case of object preposing. Language and Linguistics 3(4). 695-714.

Paul, Waltraud. 2005. Low IP area and left periphery in Mandarin Chinese. Recherches linguistiques de Vincennes 33. 111-134.

Rodríguez-Mondoñedo, Miguel. 2007. The syntax of objects: Agree and differential object Marking. Storrs: University of Connecticut Dissertation.

Shyu, Shu-ing. 1995. The syntax offocus and topic in Mandarin Chinese. Los Angeles: University of Southern California dissertation.

Tieu, Lyn-Shan. 2009. Standard vs. sideward movement in verb copying. In Yun Xiao (ed.), Proceedings of the 21st North American Conference on Chinese Linguistics (NACCL-21), volume 2, 584-600. Smithfield, Rhode Island: Bryant University.

Tsai, Wei-Tien Dylan. 1995. Visibility, complement selection and the case requirement of CP. Journal of East Asian Linguistics 4(4). 281-312.

Tsai, Wei-Tien Dylan. 2009. Actuality entailments and topography of Chinese modals. Paper presented at the 7th GLOW Conference in Asia, The English and Foreign 
Languages University, 25-28 February.

Tsai, Wei-tien Dylan. 2010. Tan hanyu motaici qi fenbu yu qunshi de duiying guanxi [On the syntax semantics correspondences of Chinese modals]. Zhongguo Yuwen [Studies of the Chinese language] 3: 208-221.

Tsao, Feng-fu. 1987a. A topic-comment approach to the Ba construction. Journal of Chinese Linguistics 15(1). 1-55.

Tsao, Feng-fu. 1987b. On the so-called verb-copying construction in Chinese. Journal of the Chinese Language Teachers Association 22(2). 13-44.

van Bergen, Geertje. 2006. To ba or not to ba: Differential object marking in Chinese. Nijmegen: Radboud University thesis.

Yang, Ning \& Geertje van Bergen. 2007. Scrambled objects and case marking in Mandarin Chinese. Lingua 117(9). 1617-1653.

Mailing address: Department of Foreign Languages, National Chiayi University No.85, Wunlong Village, Minsyong Township, Chiayi County 621, Taiwan

Email: domo@mail.ncyu.edu.tw

Received: $\quad$ February 11, 2014

Accepted: $\quad$ August 1, 2014 
漢語動詞重複句中側邊移動之構成要素

$$
\text { 郭珮蓉 }
$$

國立嘉義大學外國語言學系

提要

本篇文章探討由 Cheng (2007) 對動詞拷貝結構所提出的側邊移動之句法成份。本文 首先檢視動詞拷貝結構中的結果之得 - 子句次類，並指出在鄭的分析下，有些事實似 乎需要再解釋。因此以 Cheng (2007) 為基礎，本文提出一個延伸的分析。在此延伸 的分析中，本文提出在結果之得 - 子句次類中所涉及的側邊移動機制可以更進一步 分析為內主題化加上受詞區別標記。再者，此種對側邊移動的分析在方式之得 - 子 句中也可得到驗證。最後，不論是在漢語本身或跨語言比較方面，本文提出的內主 題化和受詞區別標記這兩種句法機制，都是廣泛存在的。

關鍵詞

動詞拷貝，標準移動，側邊移動，內主題化，受詞區別標記，把字句 